\title{
HPV genotypes in the oral cavity/oropharynx of children and adolescents: cross-sectional survey in Poland
}

\author{
Julia Durzyńska • Joanna Pacholska-Bogalska • \\ Maria Kaczmarek • Tomasz Hanć • Magdalena Durda • \\ Magdalena Skrzypczak • Anna Goździcka-Józefiak
}

Received: 27 July 2010 /Accepted: 3 November 2010 / Published online: 24 November 2010

(C) The Author(s) 2010. This article is published with open access at Springerlink.com

\begin{abstract}
Human papillomaviruses (HPVs) are a very complex group of pathogenic viruses, with more than 80 types, causing human infection. Given the prevalence of HPV infection and its relationship with the development of cervical and many other cancers, HPV vaccine development has been a major public health initiative worldwide in the last decade. The aim of the presented study was to identify HPV DNA by MY-PCR in 4,150 school children and adolescents, aged 10-18 years in the Wielkopolska region, Poland. All individuals were asked to fill in extensive questionnaires; further normal, oral squamous cells were collected from each pupil. Cellular DNA was isolated and used as a MY-PCR template to estimate the incidence of HPV-active infection. Forty five subjects (1.08\% of the sample) were carriers of oropharyngeal HPVs. HPV status and variables of interest, such as age, gender, socioeconomical status, and risk factors (smoking and sexual intercourse history, alcohol consumption) were
\end{abstract}

\footnotetext{
J. Durzyńska $(\bowtie) \cdot$ J. Pacholska-Bogalska •

A. Goździcka-Józefiak

Department of Molecular Virology, Faculty of Biology,

Adam Mickiewicz University,

ul. Umultowska 89

61-614, Poznań, Poland

e-mail: juliadur@amu.edu.pl

M. Kaczmarek • T. Hanć • M. Durda • M. Skrzypczak

Department of Human Biological Development,

Faculty of Biology, Adam Mickiewicz University,

ul. Umultowska 89,

61-614, Poznań, Poland

J. Pacholska-Bogalska

Department of Animal Physiology and Development,

Adam Mickiewicz University,

ul. Umultowska 89,

61-614, Poznań, Poland
}

not correlated. The presence of HPVs in the oral cavity was cumulated in several schools of the region. DNA sequencing of MY-PCR products revealed only four HPV genotypes. The most frequent genotype was HPV11 (38/45 HPV-positive cases), while other more rare genotypes were HPV6 (3/45), HPV12 (3/45), and HPV57 (1/45). Conclusion: Our findings presented herein, reveal a relatively low prevalance of oropharyngeal HPVs in Polish adolescents and fill an important gap in the knowledge of oral HPV infections of children above 10 years and adolescents.

Keywords HPV infection · Oral cavity/oropharynx · Prevalence $\cdot$ Adolescents

\section{Introduction}

Human papillomaviruses (HPVs) are small double-stranded DNA tumor viruses infecting oral mucosa and genital tracts; many HPV genotypes are found in both these localizations. HPVs responsible for benign epithelial hyperproliferation are named "low-risk" types (HPV-LR), while HPVs associated with premalignant lesions and invasive squamous cell carcinoma are named "high-risk" types (HPV-HR) [5, 23]. In the head and neck, HPV infections may result in benign lesions of the oral cavity and larynx or in squamous cell carcinoma in the oropharynx [8]. HPVs are not only found in cancer tissues but also detected in normal oral mucosa of healthy individuals [15]. Although HPV infection is transmitted mainly by sexual contacts, it may also be transmitted by skin-to-skin contacts [18]. It has been proposed that HPV infection of normal skin is acquired very early in infancy [1]. Several modes of HPV transmission during birth were proposed by birth canal, transplacental infection or amniotic fluid [20]. In the oral 
cavity, 24 HPV genotypes (HPV-1, 2, 3, 4, 6, 7, 10, 11, 13, $16,18,30,31,32,33,35,45,52,55,57,59,69,72$ and 73 ) have been shown to be present in benign lesions and 12 HPV genotypes (HPV-2, 3, 6, 11, 13, 16, 18, 31, 33, 35, 52 and 57) in malignant lesions [9]. According to Syrjanen et al. the list of HPV genotypes found in the oral cavity is even longer and includes also HPV-58 genotype [21]. Many reports about oral HPV prevalence in the oropharynx in geographically distant human populations are available from cross-sectional surveys $[3,10,17,19,20,22]$. However, different methodological approaches make difficult to compare HPV frequencies and patterns of HPV genotypes in normal oral mucosa among studied groups. Therefore, HPV prevalence varies from one study to another and remains controversial [4].

It should be noted that there are very few population-based screening programs restricted to small areas in Poland [2]. The purpose of the present study was to investigate the prevalence and genotypes of HPV in the oral cavity of children and adolescents in the Wielkopolska region, Poland. It is the first epidomiological cross-sectional survey conducted in children and adolescents in Poland. Our data provide novel information, still missing in Poland [11], about HPV occurrence in the oral cavity/oropharynx in young Polish population, aged $10-18$.

\section{Materials and methods}

Sampling design

Data were collected in years 2008-2009 as part of a large ongoing cross-sectional population-based survey of adolescents in the Wielkopolska region named ADOPOLNOR (www.adopolnor.eu). This region, with 3.4 million population, is situated in the central west of Poland and covers $29,826.51 \mathrm{~km}^{2}$. The study population consisted of 2,028 boys and 2,122 girls, aged 10-18 years, pupils of all types of schools, residing in rural and urban areas of the Wielkopolska region. The examination included body height and weight measurements and an extensive questionnaire where adolescents reported their state of health, health-risk behaviours, such as smoking cigarettes, drinking alcohol, taking drugs, and practicing risky sexual activities and socioeconomic life conditions of their households.

Biological samples-collection and preparation

Oral squamous cells from all the studied subjects $(n=4150)$ were collected as an oral rinse with a saline solution $(5 \mathrm{~mL})$ and processed to cellular DNA extraction, as previously described [7]. DNA concentration obtained from buccal swabs ranged from 10 to $30 \mathrm{ng} / \mathrm{ul}$.
Detection of HPV DNA by MY-PCR, sequencing and preparation of DNA standards

All these steps were performed as described in previous studies $[6,13]$.

\section{Statistical analyses}

For statistical analysis, all subjects were grouped by age (10-12; 13-15, and 16-18 years), type of school, and residence. The urbanization factor was categorized as follows: place of residence_-village (up to 20,000 residents), town (up to 500,000 residents), and city (over 500,000 residents). The school type was classified into primary, lower secondary, and higher secondary.

The Pearson's chi-square test was used to estimate relation between HPV prevalence and variables of interest. Computations were performed using the Statistica 7.1 software package (StatSoft. Inc. 2005 Statistica for Windows). Statistical decisions were taken with a $5 \%$-error probability.

\section{Results}

The study sample included 4,150 children and adolescents of caucasian race. This racial homogeneity is typical for Polish population and relatively rare in the world. There were slightly more girls than boys in the study sample (51.13\% versus $48.87 \%)$. For more detailed description of sociodemographic data of the participants evaluated in the investigation, refer to Table 1.

The total prevalence of HPV in the oral cavity was $1.08 \%$ and four different HPV genotypes were detected. More HPV-positive individuals were among girls (53.3\%). No correlation was found between HPV prevalence and diseases of upper respiratory tract diagnosed by clinicians in the study group (including chronic diseases, such as asthma, tuberculosis, mucoviscidosis; these variables were not included in Table 2). The distribution of positive cases for infections with HPV was almost even as far as the different sizes of places of residence in the Wielkopolska region is concerned. For details, see Table 2. Correlations between HPV prevalence in the oral cavity and age, gender, socioeconomical status, as well as several risk factors enhancing HPV-related cell transformation, as described in literature (smoking, alcohol consumption, and sexual intercourse history), were sought, but none was observed. Smoking and alcohol consumption categories were not included in Table 2.

After the initial MY-PCR amplification, over 53 samples could be classified as positive for HPV DNA presence. In order to confirm these results, a second round of MY-PCR was performed; eight probes were negative for the presence 
Table 1 General characteristics of the study sample

\begin{tabular}{|c|c|c|c|}
\hline & Variables & Number & $\%$ \\
\hline \multirow[t]{2}{*}{ Gender } & Boys & 2,028 & 48.87 \\
\hline & Girls & 2,122 & 51.13 \\
\hline \multirow[t]{3}{*}{ Age (years) } & $10-12$ (primary school) & 1,313 & 31.64 \\
\hline & $13-15$ (secondary school) & 1,551 & 37.37 \\
\hline & 16-18 (high school) & 1,286 & 30.99 \\
\hline \multirow[t]{3}{*}{ Place of residence ${ }^{a}$} & Village & 1,603 & 38.63 \\
\hline & Town: $21,000-500,000$ inhabitants & 1,675 & 40.36 \\
\hline & City over 500,000 inhabitants & 807 & 19.45 \\
\hline \multirow[t]{3}{*}{ Socio-economic status (SES) - on the basis of complex indicator) ${ }^{\mathrm{b}}$} & Low & 1,338 & 32.24 \\
\hline & Average & 1,301 & 31.35 \\
\hline & High & 1,401 & 33.76 \\
\hline \multirow[t]{3}{*}{ Sexual intercourse ${ }^{c}$} & No & 2,356 & 86.52 \\
\hline & Yes, once & 103 & 3.78 \\
\hline & Yes, more than once & 264 & 9.69 \\
\hline
\end{tabular}

${ }^{a} 65$ individuals did not state their place of residence (blank space in the questionnaire)

${ }^{\mathrm{b}}$ One hundred and ten individuals did not state their SES (blank space in the questionnaire)

${ }^{\mathrm{c}}$ Only adolescents (13-15 and 16-18 age categories) were asked with question about sexual intercourse $(N=2,837)$. 114 individuals did not want to answer this question (blank space in the questionnaire), thus $N=2,723$ in this category

of 450-bp HPV amplicon and were excluded from further analysis to avoid overestimation of positive results. It might have been due to the lack of viral DNA stability and/or too low viral DNA copy numbers very close to the detection threshold using MY-PCR method. In any case, the 450-bp HPV amplicon was redetected in 45 probes. The presence of HPV DNA was additionally confirmed and checked for HPV genotypes by direct DNA sequencing from PCR reaction tube (without purification from MY09 and MY11 oligonucleotides), even though the ethidium bromide signal from the 450-bp HPV amplicon had been very weak (hardly visible) in agarose gel after electrophoresis of several probes. In general, "seq files" contained sequences of perfect readability covering over 300-400 nucleotides; in three cases, only 50-100 nucleotides could have beed read because of numerous " $N$ " nucleotides (background noise). With the help of the corresponding chromatogram file, they were easily corrected. In either case, assigning HPV genotype to each sequence was possible.

In our study group, none of HPV-HR types was detected, while among HPV-LR types, HPV-11 (38/45 HPV-positive cases), HPV-6 (3/45 HPV-positive cases), HPV-57 (3/45

Table 2 HPV prevalence and selected features of the study sample

\begin{tabular}{|c|c|c|c|c|c|}
\hline Variables & Category & Number of HPV-infected individuals & Chi-square & df & $P$ value \\
\hline Gender & $\begin{array}{l}\text { Boys } \\
\text { Girls }\end{array}$ & $\begin{array}{l}21 \\
24\end{array}$ & 0.086 & 1 & 0.7690 \\
\hline Age & $\begin{array}{l}10-12 \\
13-15 \\
16-18\end{array}$ & $\begin{array}{l}9 \\
22 \\
14\end{array}$ & 3.56 & 2 & 0.1685 \\
\hline Place of residence & $\begin{array}{l}\text { Village: up to } 20,000 \text { inhabitants } \\
\text { Town: } 21,000-500,000 \text { inhabitants } \\
\text { City: over } 500,000 \text { inhabitants }\end{array}$ & $\begin{array}{l}13 \\
17 \\
15\end{array}$ & 5.595 & 2 & 0.0610 \\
\hline SES & $\begin{array}{l}\text { Low } \\
\text { Average } \\
\text { High }\end{array}$ & $\begin{array}{l}13 \\
16 \\
16\end{array}$ & 0.41 & 2 & 0.8150 \\
\hline Sexual intercourse* & $\begin{array}{l}\text { No } \\
\text { Yes, once } \\
\text { Yes, more than once }\end{array}$ & $\begin{array}{l}34 \\
0 \\
2\end{array}$ & 2.29 & 2 & 0.3180 \\
\hline
\end{tabular}

*Only adolescents (13-15 and 16-18 age categories) were asked with question about sexual intercourse $(N=2,837)$. 114 individuals did not want to answer this question (blank space in the questionnaire), thus $N=2,723$ in this category 
HPV-positive cases), and HPV-12 (1/45 HPV-positive cases) were found (Table 3).

\section{Discussion}

A great variation in HPV rates detected in the oral mucosa of healthy individuals was reported, and it depends on the population studied and the choice of method. It is also known that HPV occurrence in the normal oral mucosa comprises sublinical and/or latent infections; Moreover, HPV infections of low viral load are frequent in the oral cavity [4]. Given the abundance of literature describing results concerning HPV prevalence in the oral cavity and oropharynx all over the world, data presented in this study are to be compared to similar surveys, which were conducted on adolescents aged 10-18 years old using the same MY-PCR method.

In the present study, HPV-11 genotype was detected at surprisingly high rate (38/45 HPV-positive cases), while HPV-6 type, frequently reported to be present in the oropharynx, was detected only in three cases (3/45 HPVpositive cases). In our concurrent study, HPV-6 genotype has been identified in $30 \%$ cases of juvenile-onset recurrent respiratory papillomatosis among 47 patients investigated (3-12 year old) [6]. Concordant results concerning high HPV-11 prevalence in normal oral mucosa were not reported in literature. One should keep in mind that in some cases, localized HPV-11 infection may lead to severe clinical symptoms, such as recurrent respiratory papillomatosis mentioned above, or genital warts if infection is transmitted [12]. Another important finding of our study was the HPV-57 type present in three HPV-positive samples (3/45 HPV-positive cases). This HPV type had been previously found in numerous locations (inverted papillomas of the maxillary sinus, an oral verruca, and a genital condyloma) [14]. In rare cases, both HPV-11 and HPV-57 types are detected in malignant tumors. HPV-11 is known, especially for transformation of cells of the larynx and lungs, while HPV-57 of the nasal cavity.

It was also surprising to detect HPV-12 genotype in one specimen, because in the majority of studies, it was not mentioned to infect buccal mucosa $[9,21]$ and is rather considered to be etiologically significant in cutaneous epidermodysplasia verruciformis (EV)-associated HPV (EV-HPV). However, HPV-12 tends also to persistently infect within oral mucosa as shown in the study on HPV prevalence in Japan [10].

In the present study HPV-HR genotypes were not detected, whereas their presence was reported at relatively high rate in similar studies by other researchers $[19,20]$. It may be due to the MY-PCR method, solely employed in our experimental procedure. It has been reported that typespecific nested PCR greatly improves detection limit of HPV-16 in buccal samples, setting it below ten viral DNA copies [16]. However, in one study performed with the sole usage of MY09 and MY11 oligonucleotides in PCR reaction, HPV-16 DNA was detected in one sample (among 662 screened). The detection limit was set at 100 viral copies in that study [10]. These results could support ours, in which case, indeed HPV-HR types were not present in the study sample of Polish adolescents or HPV-HR DNA load was significantly lower (several viral copies) than the viral load of detected HPV-LR genotypes.

The overall HPV prevalence in the study group was $1.08 \%$, and its distribution was even among different strata of age. This observation remains in opposition to those from other studies establishing that HPV prevalence depends strongly upon age [19]. Whereas the HPV prevalence reported herein is low and consistent with the results mentioned above; where the mean HPV prevalence in the 12-15 year-old group of American adolescents was $1.5 \%[19]$.

In the present study correlations between HPV, prevalence and other variables were not observed. Concordant results were described in a number of studies [19, 20]; where sociodemographic gender, sexual intercourse (only adolescents over 13 years old were asked the question about their sexual activity), smoking cigarettes, and drinking were taken into account. In our study correlation of HPV, prevalence with upper respiratory chronic diseases (such as asthma, tuberculosis, mucoviscidosis) was also sought but was not observed. However, it is noteworthy that in several schools, localized in small towns around Poznań and in Poznań itself, the number of HPV-positive children/adolescents was elevated (not included in Table 2).
Table 3 Prevalence of HPV genotypes in the study sample

\begin{tabular}{lccc}
\hline HPV genotype & $N$ (HPV-positive cases) & \% (out of $N=4,150)$ & HPV genotype/all HPV cases \\
\hline HPV11 & 38 & 0.92 & $38 / 45$ \\
HPV6 & 3 & 0.07 & $3 / 45$ \\
HPV57 & 3 & 0.07 & $3 / 45$ \\
HPV12 & 1 & 0.02 & $1 / 45$ \\
All HPV cases & 45 & 1.08 & \\
\hline
\end{tabular}


A non-invasive method for oral squamous cells collection, DNA extraction, and HPV DNA detection described herein are suitable for large cross-sectional studies of children and adolescents.

Acknowledgments Financial support for this work is gratefully acknowledged from a grant from Norway through the Norwegian Financial Mechanism. Project PL0255. This study has been approved by the Bioethics Committee of the University of Medical Sciences in Poznań, Poland.

Open Access This article is distributed under the terms of the Creative Commons Attribution Noncommercial License which permits any noncommercial use, distribution, and reproduction in any medium, provided the original author(s) and source are credited.

\section{References}

1. Antonsson A, Karanfilovska S, Lindqvist PG, Hansson BG (2003) General acquisition of human papillomavirus infections of skin occurs in early infancy. J Clin Microbiol 41(6):2509-2514

2. Bardin A, Vaccarella S, Clifford GM et al (2008) Human papillomavirus infection in women with and without cervical cancer in Warsaw, Poland. Eur J Cancer 44(4):557-564

3. Cason J, Mant CA (2005) High-risk mucosal human papillomavirus infections during infancy \& childhood. J Clin Virol 32(Suppl 1): S52-S58

4. Castro TP, Bussoloti Filho I (2006) Prevalence of human papillomavirus (HPV) in oral cavity and oropharynx. Braz J Otorhinolaryngol 72(2):272-282

5. Clifford GM, Smith JS, Plummer M et al (2003) Human papillomavirus types in invasive cervical cancer worldwide: a meta-analysis. Br J Cancer 88(1):63-73

6. Durzyńska J, Błażejewska P, Szydlowski J, Goździcka-Józefiak A (2010) Detection of anti-HPV11-L1 antibodies in immune sera from patients suffering from recurrent respiratory papillomatosis using ELISA. Viral Immunol 23(4):415-423

7. Durzyńska J, Pacholska-Bogalska J, Kaczmarek M et al. (2010) Multiplex PCR for identification of herpes virus infections in adolescents. J Med Virol [in press]

8. Franceschi S, Muñoz N, Snijders PJ (2000) How strong and how wide is the link between HPV and oropharyngeal cancer. Lancet 356(9233):871-872
9. Kojima A, Maeda H, Kurahashi N et al (2003) Human papillomaviruses in the normal oral cavity of children in Japan. Oral Oncol 39(8):821-828

10. Kurose K, Terai M, Soedarsono N et al (2004) Low prevalence of HPV infection and its natural history in normal oral mucosa among volunteers on Miyako Island, Japan. Oral Surg Oral Med Oral Pathol Oral Radiol Endod 98(1):91-96

11. Lévy-Bruhl D, Bousquet V, King LA et al (2009) The current state of introduction of HPV vaccination into national immunisation schedules in Europe: results of the VENICE 2008 survey. country specific VENICE gate keepers and contact points. Eur J Cancer 45 (15):2709-2713

12. Mammas IN, Sourvinos G, Spandidos DA (2009) Human papilloma virus (HPV) infection in children and adolescents. Eur J Pediatr 168(3):267-273

13. Manos MM, Ting Y, Wright DK et al (1989) The use of polymerase chain reaction amplification for the detection of genital human papillomaviruses. Cancer Cell 7:209-214

14. Marquart JD, Trakimas CA, Sawchuk WS et al (2006) Human papillomavirus 57-induced extensive, recalcitrant cutaneous verrucae. J Am Acad Dermatol 55(5):907-908

15. Miller CS, Johnstone BM (2001) Human papillomavirus as a risk factor for oral squamous cell carcinoma: a meta-analysis, 1982-1997. Oral Surg Oral Med Oral Pathol Oral Radiol Endod 91(6):622-635

16. Rice PS, Mant C, Cason J et al (2000) High prevalence of human papillomavirus type 16 infection among children. J Med Virol 61 (1):70-75

17. Rintala MA, Grénman SE, Järvenkylä ME et al (2005) High-risk types of human papillomavirus (HPV) DNA in oral and genital mucosa of infants during their first 3 years of life: experience from the Finnish HPV Family Study. Clin Infect Dis 41:1728-1733

18. Sinal SH, Woods CR (2005) Human papillomavirus infections of the genital and respiratory tracts in young children. Semin Pediatr Infect Dis 16(4):306-316

19. Smith EM, Swarnavel S, Ritchie JM et al (2007) Prevalence of human papillomavirus in the oral cavity/oropharynx in a large population of children and adolescents. Pediatr Infect Dis J 26 (9):836-840

20. Summersgill KF, Smith EM, Levy BT et al (2001) Human papillomavirus in the oral cavities of children and adolescents. Oral Surg Oral Med Oral Pathol Oral Radiol Endod 91(1):62-69

21. Syrjänen S (2003) Human papillomavirus infections and oral tumors. Med Microbiol Immunol 192(3):123-128

22. Syrjänen SJ (2004) HPV infections and tonsillar carcinoma. Clin Pathol 57(5):449-455

23. zur Hausen H (2002) Papillomaviruses and cancer: from basic studies to clinical application. Nat Rev Cancer 2(5):342-350 